\title{
Effects of interval sprint trainings on lactate level and heart rate in elite swimmers
}

\author{
Bülent Turna ${ }^{1}$ \\ Selma Civar Yavuz ${ }^{2}$ \\ Mahmut Alp ${ }^{3}$ \\ Kenan Işıldak ${ }^{4}$
}

\begin{abstract}
The aim of this study is to investigate the effects of interval sprint trainings on lactate level and heart rate in elite swimmers. 10 licenced swimmers ( 5 male- 5 female) participated in the study voluntarily who train regularly at the Akdeniz University Swimming Team and as individual whose mean age was $20,20 \pm 1,54$ years, the mean sport age was $9,10 \pm 1,59$ years, the mean height was $175,00 \pm 8,39 \mathrm{~cm}$ and the mean of weight was in pre-test $67,07 \pm 10,74 \mathrm{~kg}$; in post-test $67,18 \pm 10,37$ $\mathrm{kg}$. Lactate and heart rate tests were applied to the swimmers at the beginning and end of training program that was 8 weeks, 4 days a week, at least 120 minutes a day and including interval sprints in its content. Handled datas were compared by using "Paired t Test" by SPSS 22.0 statistic programme. As a result of lactate and heart rate pre and post-test values, the differences were found to be statistically significant $(\mathrm{p}<0,05)$. According to the data obtained, positive improvements were observed in the swimming performances. In addition, it has been concluded that interval sprint trainings have also positive impacts on lactate levels and heart rates. We believe that our study will make positive contribution to sportive performance of swimmers as well as providing reference values for swimming coaches applying interval trainings in swimming.
\end{abstract}

Keywords: Swimming; Interval; Sprint; Lactate; Heart Rate.

\section{Introduction}

Swimming is usually characterized by high intensity trainings in the first stages of the preparation period. At these stages, athletes' body fat rates decrease, whereas muscular strength, power production and consequently contractile and metabolic values of contraction units increase. But then, this high density decreased lays itself competition-specific training drills (Philp, Macdonald, Carter, Watt, \& Pringle, 2008; Trinity, Pahnke, Sterkel, \& Coyle, 2008).

The right training models planned at these stages are important for determining the severity of loading, for adapting to training and for tracking performance of athletes (Dekerle, Baron, Dupont, Vanvelcenaher, \& Pelayo, 2003). Therefore, interval trainings are more preferred in swimming. In swimming, interval training involves completing a certain number of swimming and repetitions with a rest interval after each swimming session.

Generally, when the repetitions' distances and the number of repetitions are very high, rest periods of 15 seconds or less tend to make the training result more aerobic. Increasing the number or range of swimming repetations produce a similar result too. Increasing the rest period usually

\footnotetext{
1 Ph.D., bulent turna@hotmail.com

2 Assoc. Prof. Dr., Akdeniz University, Faculty of Sport Sciences, scivar@akdeniz.edu.tr

${ }^{3}$ Ph.D., Süleyman Demirel University, Faculty of Sport Sciences, mahmut.alp@windowslive.com

4 Ph.D., kenanisildak@hotmail.com
} 
Turna, B., Civar Yavuz, S., Alp, M. \& Işıldak, K. (2017). Effects of interval sprint trainings on lactate level and heart rate in elite swimmers. Journal of Human Sciences, 14(2), 1435-1440. doi:10.14687/jhs.v14i2.4530

shifts the training from aerobic to anaerobic. If resting times are up to 30 seconds or more in shorter repetations and one minute or more in longer repetations, they causes a steady buildup of lactate at swimmers by swimming the sets of repetations fast (Alp ve Killnç, 2015).

The high intensity trainings that were applied in the first stages, then they leaves the same intensity of sprint trainings as the competition approaches because of the 50, 100, and 200 meters races are being held in the swimming competitions in our country. An ideal sprinter swimmer is an indicator that lactate accumulation at the upper levels will last longer than maximal loads (Costill, Tüzen).

In this respect, the aim of this study is to investigate the effects of interval sprint trainings on lactate level and heart rate in elite swimmers.

\section{Method}

Participants: 10 licenced swimmers ( 5 male- 5 female) participated in the study voluntarily who train regularly at the Akdeniz University Swimming Team and as individual whose mean age was $20,20 \pm 1,54$ years, the mean sport age was $9,10 \pm 1,59$ years, the mean height was $175,00 \pm 8,39 \mathrm{~cm}$ and the mean of weight was in pre-test $67,07 \pm 10,74 \mathrm{~kg}$; in post-test $67,18 \pm 10,37 \mathrm{~kg}$. All the sportsmen participating in the study were informed about the study and the best and most healthy measurements were made available. "Informed Consent Form" was also taken from the swimmers. All the measurements were taken by the same people as "pre-test" and "post-test" in Akdeniz University Swimming Pool.

Training Model: Swimming trainings were applied for 8 weeks, 4 days a week, at least 120 minutes a day. In the interval sprint training sessions specified in the training program, each swimmer was allowed to practice his/her own best style of interval repetations.

Table 1. Weekly Training Content

\begin{tabular}{|c|c|c|c|c|}
\hline DAYS & MONDAY & WEDNESDAY & FRIDAY & SATURDAY \\
\hline $\begin{array}{l}\text { Content of } \\
\text { Training }\end{array}$ & SPR-2, SPR-3, END-1 & END-2, END-1 & SPR-2, SPR-3, END-1 & END-1, SPR-1 \\
\hline \multirow{12}{*}{$\begin{array}{l}\text { Training } \\
\text { Drills }\end{array}$} & 600 m warm-up & 800 m warm-up & 600 m warm-up & $800 \mathrm{~m}$ warm-up \\
\hline & 10 min rest & 10 min rest & 10 min rest & 10 min rest \\
\hline & $\begin{array}{c}4 \times 100 \mathrm{~m} \\
(1 \mathrm{~min} \text { rest })\end{array}$ & $200 \mathrm{~m}$ softening & $\begin{array}{c}4 \mathrm{x} 100 \mathrm{~m} \\
(1 \mathrm{~min} \text { rest })\end{array}$ & $8 \times 50$ kick choice \\
\hline & $200 \mathrm{~m}$ softening & $\begin{array}{l}2 \times 500 \text { freestyle } \\
(35 \text { sec rest) }\end{array}$ & $200 \mathrm{~m}$ softening & 5 min rest \\
\hline & $\begin{array}{c}8 \times 50 \mathrm{~m} \text { - all styles } \\
(30 \mathrm{sec} \text { rest })\end{array}$ & $\begin{array}{l}2 \times 400 \text { freestyle } \\
(30 \text { sec rest) }\end{array}$ & $\begin{array}{c}8 \times 50 \mathrm{~m} \text { - all styles } \\
(30 \mathrm{sec} \text { rest })\end{array}$ & $8 \times 50$ pull buoy \\
\hline & $\begin{array}{c}4 \times 25 \mathrm{~m} \text { - freestyle } \\
(20 \mathrm{sec} \text { rest })\end{array}$ & $\begin{array}{l}2 \times 300 \text { freestyle } \\
(25 \text { sec rest })\end{array}$ & $\begin{array}{c}4 \times 25 \mathrm{~m} \text { - freestyle } \\
(20 \mathrm{sec} \text { rest })\end{array}$ & 5 min rest \\
\hline & $200 \mathrm{~m}$ softening & $\begin{array}{l}\text { 2x200 freestyle } \\
\text { (20 sec rest) }\end{array}$ & $200 \mathrm{~m}$ softening & $8 \times 50$ freestyle \\
\hline & $\begin{array}{l}\text { 1x500 freestyle } \\
(35 \mathrm{sec} \text { rest) }\end{array}$ & $\begin{array}{l}2 \times 100 \text { freestyle } \\
(15 \text { sec rest })\end{array}$ & $\begin{array}{l}\text { 1x500 freestyle } \\
(35 \mathrm{sec} \text { rest })\end{array}$ & 5 min rest \\
\hline & $\begin{array}{l}1 \times 400 \text { freestyle } \\
(30 \mathrm{sec} \text { rest })\end{array}$ & $\begin{array}{l}\text { 10x50 own style } \\
\text { (10 sec rest) }\end{array}$ & $\begin{array}{l}\text { 1x400 freestyle } \\
(30 \text { sec rest) }\end{array}$ & $200 \mathrm{~m}$ softening \\
\hline & $\begin{array}{c}\text { 1x300 freestyle } \\
(25 \mathrm{sec} \text { rest })\end{array}$ & 200 m kick choice & $\begin{array}{l}\text { 1x300 freestyle } \\
(25 \mathrm{sec} \text { rest })\end{array}$ & 400 cooldown \\
\hline & $\begin{array}{l}\text { 1x200 freestyle } \\
(20 \text { sec rest) }\end{array}$ & $200 \mathrm{~m}$ cooldown & $\begin{array}{l}\text { 1x200 freestyle } \\
(20 \mathrm{sec} \text { rest })\end{array}$ & \\
\hline & $\begin{array}{l}\text { 1x100 freestyle } \\
(15 \mathrm{sec} \text { rest })\end{array}$ & & $\begin{array}{l}\text { 1x100 freestyle } \\
(15 \mathrm{sec} \text { rest })\end{array}$ & \\
\hline
\end{tabular}


Turna, B., Civar Yavuz, S., Alp, M. \& Işıldak, K. (2017). Effects of interval sprint trainings on lactate level and heart rate in elite swimmers. Journal of Human Sciences, 14(2), 1435-1440. doi:10.14687/jhs.v14i2.4530

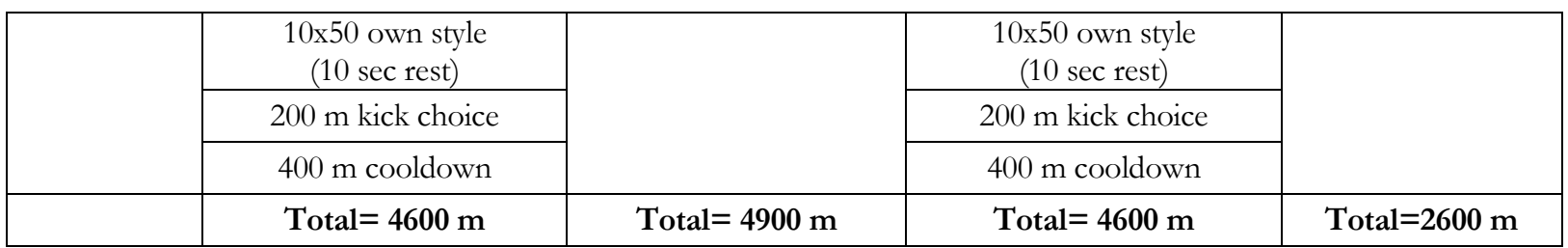

$\mathrm{m}:$ meter/s, min: minute/s, sec: second/s

\section{Measures}

Measurement of Height: Measurements were conducted with the subjects standing upright barefoot, in deep inspiration. A measuring steel scale was placed against the head and the span between the sole and the top of the head was measured with a margin error of $0,5 \mathrm{~cm}$.

Measurement of Weight: Measurements were done with an electronic scale (SECA) with 0,5 kg fallibility. The subjects were weighed barefoot in shorts and t-shirts.

Measurement of Heart Rate: Heart rate values were recorded by using the Polar RS-400 (USA) multi-pulse control watch and chest strap as "rested" and "maximal" after the athletes' $100 \mathrm{~m}$ sprint swimming performances.

Measurement of Lactate Levels: Lactate values were recorded by using Nova Lactate Plus brand $0.1 \mathrm{mmol} / 1$ precision which is a full blood measuring device as "rested" and "maximal" after the athletes' $100 \mathrm{~m}$ sprint swimming performances.

Data Analysis: SPSS 22.0 program was used in this study to obtain statistical results. "ShapiroWilk" Test was used in order to determine whether datas show normal distribution or not. "Paired t Test" was used in order to determine differences between pre and post-tests according to normal distribution defined. Results were evaluated according to " 0,05 ” significance level.

\section{Findings}

Table 2. Comparison of Swimmers' Heart Rate Pre and Post Test Values

\begin{tabular}{|c|c|c|c|c|c|}
\hline & & Test Sequence & Mean士SD & $\mathbf{t}$ & $\mathrm{p}$ \\
\hline \multirow{4}{*}{$\begin{array}{l}\text { Heart Rate } \\
\text { (number/min) }\end{array}$} & \multirow{2}{*}{ Rested } & Pre Test & $66,1 \pm 7,97$ & \multirow{2}{*}{9,76} & \multirow{2}{*}{, $000 *$} \\
\hline & & Post Test & $60,1 \pm 6,47$ & & \\
\hline & \multirow{2}{*}{ Maximum } & Pre Test & $167,3 \pm 12,03$ & \multirow{2}{*}{17,55} & \multirow{2}{*}{, $000 *$} \\
\hline & & Post Test & $158,6 \pm 11,47$ & & \\
\hline
\end{tabular}

$$
{ }^{*} \mathrm{p}<0,05
$$

There were found differences statistically as a result of comparison in pre and posttest values resting and maximal heart rate of swimmers $(p<0.05)$. 
Turna, B., Civar Yavuz, S., Alp, M. \& Işıldak, K. (2017). Effects of interval sprint trainings on lactate level and heart rate in elite swimmers. Journal of Human Sciences, 14(2), 1435-1440. doi:10.14687/jhs.v14i2.4530

Table 3. Comparison of Swimmers' Lactate Level Pre and Post Test Values

\begin{tabular}{|c|c|c|c|c|c|}
\hline & & Test Sequence & Mean \pm SD & $\mathbf{t}$ & $\mathrm{p}$ \\
\hline \multirow{5}{*}{$\begin{array}{l}\text { Lactate Level } \\
(\mathrm{mmol} / \mathrm{l})\end{array}$} & & Pre Test & $1,73 \pm, 33$ & \multirow{2}{*}{7,15} & \multirow{2}{*}{, $000^{*}$} \\
\hline & & Post Test & $1,36 \pm .26$ & & \\
\hline & & & & & \\
\hline & \multirow{2}{*}{ Maximum } & Pre Test & $13,60 \pm 1,74$ & \multirow{2}{*}{$-11,50$} & \multirow{2}{*}{, $000^{*}$} \\
\hline & & Post Test & $14,06 \pm 1,64$ & & \\
\hline
\end{tabular}

${ }^{*} \mathrm{p}<0,05$

Differences were found to be statistically significant as a result of comparison in pre and posttest values resting and maximal lactate level of swimmers $(\mathrm{p}<0.05)$.

The aim of this study is to investigate the effects of interval sprint trainings on lactate level and heart rate in elite swimmers. 10 swimmers participated in the study voluntarily who train regularly at the Akdeniz University Swimming Team.

As results of comparison of swimmers' heart rate values, differences found to be statistically significant $(\mathrm{p}<0,05)$.

Machado et al. (2011) determined the effect of 12 weeks of training on the critical velocity and maximal lactate steady state of elite swimmers. They found significant difference between pre and post-test values of rested lactate level. This result has been reported in the study and several studies in which it was suggested that individuals who undergo endurance training have a higher rate of lactate removal due to an increase in oxidative capacity.

Kan (2009) aimed to investigate the effects of the 12 week anaerobic training programme on the level of blood lactate and electrolyte of the male taekwondo athletes. Before and after training programme, differences found to be statistically significant in pre and post-tests.

Bouhlel et al. (2006)'s research, lactate levels they found significant differences after Shuttle Run Test results of Taekwondo athletes.

Marcus et al. (2011) aimed to investigate the effect of 12 weeks of training on critical velocity and maximal lactate in swimmers. They found significant differences in pre and post-test lactate levels.

Atabek (2009) specified in his research that some sports in which requires sprint repeats and power causes significant maximal lactate accumulation. According to the aim, adaptation mechanism of strength training and especially those related with metabolic stimulus have been demonstrated. The effects of three general types of strength training used in practice on the acute lactate production has also been examined: hypertrophy training controlled movements, moderate loads, short rest periods and high total work; neuronal training with explosive intent, heavy loads, long rest periods and lower total work; dynamic power training with explosive and/or ballistic movements, light loads, moderate rest periods, lower total work.

Filiz (2010) investigated the lactate levels of wrestlers after maximal load. He also found significant differences. He stated that maximal lactate was very important for wrestling so a wrester must have reached this level in trainings.

Dölek (1994) investigated the effects of short-term exercises on lactate metabolism. She found that short-term exercises increase the maximal lactate level, but it can be improved by trainings.

Dekerle et al. (2003) researched maximal lactate with respiratory compensation threshold and critical power. They found significant maximal lactate levels pre and post-test values. According to the authors these values do not represent the maximal work rate that can be maintained for a 
Turna, B., Civar Yavuz, S., Alp, M. \& Işıldak, K. (2017). Effects of interval sprint trainings on lactate level and heart rate in elite swimmers. Journal of Human Sciences, 14(2), 1435-1440. doi:10.14687/jhs.v14i2.4530

long period of time without a continuous rise of blood. Thus, an accurate and reliable evaluation of aerobic endurance can only be realized from a direct, but long and tedious method of maximal lactate determination.

Toubekis and Tokmakidis (2013) examined metabolic responses at various intensities relative to critical swimming velocity. They stated that swimming distances required velocity, increases the maximal lactate level and threshold. In addition they defined that lactate responses during interval training may be steady or decreasing in children, steady in adult but possibly increasing in young swimmers, showing exercise at the heavy or very heavy domain.

Akbaş et al. determine the lactate levels of male elite $100 \mathrm{~m}$ athletes whose best times are under 11 seconds in Turkey, both before and after 100m running. They defined an increase during the $100 \mathrm{~m}$ running observed in the lactate levels of the subjects. That is thought of anaerobic glycolysis supports to ATP-CP energy system in $100 \mathrm{~m}$ running consequence of this metabolism blood lactate levels could get higher.

\section{Conclusion}

According to the data obtained, positive improvements were observed in the swimming performances. In addition, it has been concluded that interval sprint trainings have also positive impacts on lactate levels and heart rates.

Series of repetitions of defined distances are used during daily training practices in swimming. The proper planning of pace in each series of repetition is important to avoid overloading or underloading the swimmers. Intermittent swimming at intensity below velocity will maintain steady-lactate concentration. Intermittent swimming at velocity will probably progressively increase the lactate concentration. This is more likely to happen in young swimmers and less likely to happen in adult swimmers, while lactate may decrease in child swimmers. Progressive increase of lactate concentration is also more likely to be observed when the velocity swimming has been calculated from distances of short duration (i.e., 50, 100, 200, and $400 \mathrm{~m}$ ) and less likely when at least one distance of long duration has been used (i.e., 10-15 minutes).

Swimming at intensity of velocity will increase the lactate concentration and exhaust young and adult male swimmers. We believe that our study will make positive contribution to sportive performance of swimmers as well as providing reference values for swimming coaches applying interval trainings in swimming.

\section{References}

AKBAŞ, S., PELVAN, S.O., ATEŞ, O. (2011). Blood Lactate Levels of Sportsmen After $100 \mathrm{~m}$ Running. IIB International Refereed Academic Social Sciences Journal; 1: 101-107.

ALP, M., KILINÇ, F. (2015). Interval and Combine Trainings in Swimming. Turkey Alim Books, Saarbrücken/Germany, p:20-23.

ATABEK, H. (2009). Acute Lactate Produciton During Resistance Training. SPORMETRE Journal of Physical Education and Sports Science, VII (1): 29-36.

BOUHLEL, E., JOUINI, A., GMADA, N., NEFZI, A., ABDALLAH, K.B., TABKA, Z. (2006). Heart Rate and Blood Lactate Responses During Taekwondo Training and Competition, Science Sports, 21: 285-290.

COSTILL, D.L., THOMAS, R.A., PASCOE, D., LAMBERT, C., BARR, S., FINK, W.J. (1991). Adaptations to swimming training: influence of training volume. Medicine and Science Sports in Exercise, 23(3), p:371-377.

DEKERLE, J., BARON, B., DUPONT, L., VANVELCENAHER, J., PELAYO, P. (2003). Maximal lactate steady state, respiratory compensation threshold and critical power. European Journal of Applied Physiology, 89; 281-288. 
Turna, B., Civar Yavuz, S., Alp, M. \& Işıldak, K. (2017). Effects of interval sprint trainings on lactate level and heart rate in elite swimmers. Journal of Human Sciences, 14(2), 1435-1440. doi:10.14687/jhs.v14i2.4530

DÖLEK, Ç. K. (1994). Relation to lactic acid metabolism and testosterone levels in short-term exercise. Ph.D. Thesis, Unpublished. Konya: Selçuk University.

FILIZ, K. (2010). Pre-Competition Lactic Acid Levels of Wrestlers. Journal of Physical Education and Sport Sciences. February, 48-55.

KAN, Ö. (2009). The Effects of the 12 Week Anaerobic Training Programme on The Level of Blood Lactate and Electrolyte of the Male Taekwondo Athletes Between 14-16 Years Old. M.Sc Thesis Unpublished. Konya: Selçuk University.

MACHADO, M. V., JUNIOR, O. A., MARQUES, A. C., COLANTONIO, E., CYRINO, E. S., DE MELLO, M. T. (2011). Effect of 12 weeks of training on critical velocity and maximal lactate steady state in swimmers. European Journal of Sport Science, 11(3), 165-170.

PHILP, A., MACDONALD, A. L., CARTER, H., WATT, P. W., \& PRINGLE, J. S. (2008). Maximal lactate steady state as a training stimulus. International Journal of Sports Medicine, 29, 475-479.

TOUBEKIS, A. G., \& TOKMAKIDIS, S. P. (2013). Metabolic responses at various intensities relative to critical swimming velocity. The Journal of Strength \& Conditioning Research, 27(6), 1731-1741.

TRINITY, J. D., PAHNKE, M. D., STERKEL, J. A., COYLE, E. F. (2008). Maximal power and performance during a swim taper. International Journal of Sports Medicine, 29, 500_506.

TÜZEN, B., MINIROĞLU, S., TANILKAN, K. (2005). Comparison of Short Distance Swimmers with 30 Meter Speed Running Grades and 50 Meter Free Style Swimming Grades, SPORMETRE Journal of Physical Education and Sports Science, 3(3), 97-99. 